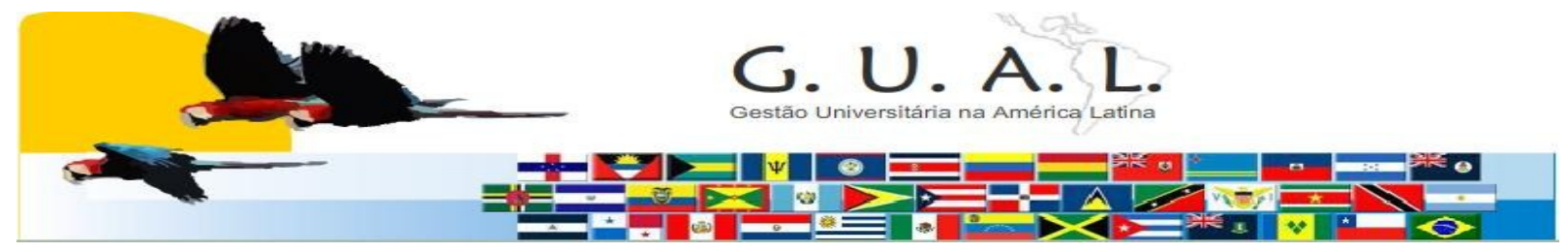

ISSN 1983-4535

\title{
A GESTÃO DO CONHECIMENTO APLICADA EM INSTITUIÇÕES DE ENSINO SUPERIOR - O CASO DA ASSOCIAÇÃO CATARINENSE DE FUNDAÇÕES EDUCACIONAIS
}

\author{
Marcos Ferasso, Doutor \\ Universidade Federal do Piauí \\ admmarcos@admmarcos.adm.br
}

Jorge Alberto Velloso Saldanha, Doutor

Universidade Federal do Piauí

javsa@terra.com.br

\section{RESUMO}

O conhecimento humano é criado e expandido através de interação social entre o conhecimento tácito e o explícito, o que se denomina conversão do conhecimento. Dessa forma, existem quatro formas de conversão de conhecimento: a socialização, a externalização, a combinação e a internalização. O presente estudo de caso busca investigar como se configura o processo de conversão do conhecimento, em instituições de ensino superior. Por meio da pesquisa, descobriu-se que existem quatro fatores de grande importância e que garantem a geração e difusão do conhecimento na ACAFE, são eles: criação de grupos ad hoc formados para unificar procedimentos e obter ações conjuntas; decisões são tomadas em colegiado, registrando atribuições e responsabilidades para cada instituição; a interação e comunicação entre os membros de câmaras setoriais se dá pela forma de listas eletrônicas, para troca de informações e experiências; e as fontes internas próprias são as principais fontes de informação e conhecimento para o desenvolvimento tecnológico. Percebeu-se que a ACAFE encontra-se em estágio avançado na gestão deste conhecimento, necessitando fortalecer os conhecimentos captados fora da ACAFE, considerados na elaboração de estratégias, além da segurança e proteção do conhecimento desenvolvido e/ou adquirido.

Palavras-chave: Gestão do conhecimento. Gestão universitária. ACAFE.

Artigo revisado e ampliado com base na versão resumida e publicada conforme a seguinte referência: FERASSO, Marcos, SALDANHA, Jorge Alberto Velloso, VIEIRA, Leandro

Mauricio Medeiros. The process of knowledge conversion in Institutions of Superior Education: the case of the Catarinian Association of Educational Foundations ACAFE/Brazil. International journal of knowledge, cultura \& change management, v. 6, p. 17, 2007. 


\section{INTRODUÇÃO}

A gestão do conhecimento é hoje uma necessidade efetivamente sentida nas empresas. Considerando que o conhecimento é um dos ingredientes mais importantes de uma organização, o gerenciamento deste tem despertado interesse quanto à obtenção de vantagens competitivas proporcionadas pela mudança de posições em um determinado mercado por meio de inovações tecnológicas.

A gestão do conhecimento poderá ser condição necessária, mas não é condição suficiente para o sucesso empresarial, devido o conhecimento ser um engenho de renovação e crescimento, desde que consciente e globalmente gerido, mas a gestão poderá incentivar e facilitar a criação e a exploração do conhecimento de forma interligada (KULKKI e KOSONEN, 2001, apud NICOLAU, 2002).

As instituições de ensino superior (IESs) têm-se destacado no cenário brasileiro por suas incessantes incursões no meio tecnológico. Em virtude das atenções estarem voltadas ao conhecimento produzido pelo ensino, pesquisa e extensão, o que se tem trabalhado em relação à gestão do conhecimento destas próprias instituições?

A partir deste fato, surge a necessidade de se conhecer o processo de gestão do conhecimento em uma associação de instituições de ensino superior, como é o caso catarinense, um caso de associação único no Brasil.

Este estudo busca responder à seguinte questão de pesquisa: "Como se configura o processo de conversão do conhecimento, em instituições de ensino superior?", tornando-se o objetivo central de pesquisa.

Assim, escolheu-se o sistema fundacional catarinense por caracterizar-se pela junção das instituições de ensino superior presentes neste estado, julgando-se suficientemente importante para realização deste estudo.

\section{REFERENCIAL TEÓRICO}

\subsection{Gestão do conhecimento}

É de extrema importância saber rapidamente o que está se passando nos negócios ou poder tomar decisões gerenciais importantes de forma rápida. Isto só é possível apenas para 


\section{A GESTÃO DO CONHECIMENTO APLICADA EM INSTITUIÇÕES DE ENSINO SUPERIOR - O CASO DA ASSOCIAÇÃO CATARINENSE DE FUNDAÇÕES EDUCACIONAIS}

empresas bem preparadas, que têm sob controle as informações sobre seus negócios, em tempo real (SCHMUKLER e ALBINO, 1999; ALMANSA et al., 2002).

Uma vez que conhecimento não é dado, nem é informação, embora esteja relacionado com ambos e as diferenças entre esses termos sejam normalmente uma questão de grau, mas deriva da informação da mesma forma que a informação deriva de dados, toda transformação da informação em conhecimento se dá através de comparação, analisando as conseqüências, buscando as conexões e conversando com outras pessoas sobre as informações recebidas.

O sucesso deste sistema se dá pela transferência espontânea e não-estruturada do conhecimento. É o valor agregado das pessoas, do contexto, suas experiências, interpretações, que transforma os dados e informações em conhecimento e é a capacidade de captar e gerir esses incrementos humanos que torna as tecnologias da informação particularmente apropriadas para lidar com o conhecimento (SCHMUKLER e ALBINO, 1999).

Assim, gerenciar a informação tem exigido ampla gama de soluções que permitam administrar grande quantidade de dados tradicionais e permitir aos usuários acessar esses dados em qualquer lugar. Possuir pessoas altamente especializadas será fundamental para a sobrevivência das corporações. As organizações aprenderem como fazer a gestão do conhecimento, tornando-se este um fator crucial e diferenciador para o sucesso. Tudo isto impacta fortemente no perfil de gestores e colaboradores para as próximas décadas, isto porque conhecimento e comunicação são os ingredientes competitivos mais importantes. As empresas serão capazes de gerenciar os conhecimentos através da absorção e propagação, via internet, dos conhecimentos acumulados (SCHMUKLER e ALBINO, 1999).

A gestão do conhecimento considera a identificação do conhecimento relevante, o que está, necessariamente ligado à estratégia empresarial que deverá assentar nas competências vitais da empresa para cuja sustentação e renovação esse conhecimento tem de contribuir (NICOLAU, 2002).

Também considera a transformação de conhecimento individual em conhecimento coletivo (a empresa é o lugar onde se cruzam saberes diversos em maioria individual). Estimular a partilha incentivando boas práticas e promovendo o abandono das mais nocivas implica um esforço prolongado de mudança nas culturas e mentalidades (NICOLAU, 2002).

Rev. GUAL., Florianópolis, Edição especial 2011, p.51-69. 


\section{A GESTÃO DO CONHECIMENTO APLICADA EM INSTITUIÇÕES DE ENSINO SUPERIOR - O CASO DA ASSOCIAÇÃO CATARINENSE DE FUNDAÇÕES EDUCACIONAIS}

A gestão também é necessária na transformação do conhecimento tácito em codificado, o que significa um esforço de tornar perceptível de forma organizada o conhecimento adquirido com a experiência, (NICOLAU, 2002).

Por fim, também deve-se considerar a promoção da aquisição de conhecimento de origem externa, o que se liga a outra questão de primeira importância que é a existência de um sistema eficiente de informação; na integração dos novos conhecimentos no conhecimento existente; e na política de retenção do conhecimento nas organizações, quer através do incentivo à partilha dos conhecimentos existentes, quer gerindo as saídas de modo a evitar a perda de conhecimento importante (NICOLAU, 2002).

No Ocidente, a gestão do conhecimento tem duas dimensões, a saber: (i) a mensuração do conhecimento, ou o "capital intelectual", mais comum na Europa; (ii) o gerenciamento do conhecimento, mais comum nas companhias americanas (TAKEUCHI (1998, apud LIMA e GOSLING, 2005).

Em termos de mensuração do conhecimento, o enfoque é nos valores "intangíveis", que podem garantir a sobrevivência das empresas e gerar vantagens competitivas. Assim, preocupa-se com o desenvolvimento de sistemas capazes de medir os intangíveis, tornando públicos os resultados (LIMA e GOSLING, 2005).

Em termos de gerenciamento, o enfoque é alcançar as melhores práticas de gestão. Assim, existem "gerentes do conhecimento", responsáveis por manter uma "base de dados de conhecimento", catalogando e formatando documentos e experiências, além de apagar o que se torna obsoleto (LIMA e GOSLING, 2005).

Para Takeuchi (1998, apud LIMA e GOSLING, 2005), quando comenta a respeito da questão do conhecimento em empresas orientais, explica que as empresas japonesas não estão convencidas a respeito do valor de simplesmente medir e gerenciar o conhecimento existente, de uma maneira mecânica e sistemática. Elas questionam se apenas isso trará inovação. As empresas japonesas buscam mais do que simplesmente gerenciar o conhecimento, buscam criá-lo. Nonaka e Takeuchi (1997, apud LIMA e GOSLING, 2005) argumentam que a organização que deseja lidar dinamicamente com as mudanças ambientais precisa criar informação e conhecimento, não apenas processá-los de forma eficiente. Além disso, os membros da organização não podem ser passivos, mas sim agentes ativos de inovação.

Rev. GUAL., Florianópolis, Edição especial 2011, p.51-69. 


\section{A GESTÃO DO CONHECIMENTO APLICADA EM INSTITUIÇÕES DE ENSINO SUPERIOR - O CASO DA ASSOCIAÇÃO CATARINENSE DE FUNDAÇÕES EDUCACIONAIS}

Nas empresas, o conhecimento criado deve ser convertido em inovações visíveis em seus produtos e/ou serviços. Para tanto, é necessário que haja maneiras de se compartilhar o conhecimento adquirido, e é nesse sentido que a gestão de conhecimento se relaciona com a aprendizagem organizacional (LIMA e GOSLING, 2005).

Senge (1990, apud LIMA e GOSLING, 2005) distinguiu dois tipos de aprendizado, o "aprendizado adaptativo", refere-se aos esforços incrementais de melhoria, tendo em vista as demandas do ambiente. Já o "aprendizado gerador ou criativo", refere-se à experimentação, ao pensamento sistêmico, à disposição para se pensar além das imitações geralmente aceitas de um problema. Novamente, pode-se perceber a relação entre criação de conhecimento (inovação) e aprendizagem (LIMA e GOSLING, 2005).

\subsubsection{Conhecimento}

O conhecimento é definido por Tanguy (2000, apud BODER e BOUTELITANE, 2005) como:

"un savoir incarné dans une personne physique. Autrement dit quelque chose qui est su par quelqu'un est une connaissance pour ce quelqu'un. La connaissance renvoie toujours à un possesseur humain à même de mettre en œuvre, elle est à la base des compétences de tout individu".

O conhecimento é o produto de informações processadas sob a influência de fatores diversos (método, linguagem, fatores psicológicos, sociais e outros conhecimentos já acumulados), informações que advém de dados percebidos no ambiente sob e através da influência deste fatores de percepção e processamento (CHERUBINI NETO, 2002).

O conhecimento é a saída de um sistema composto por sujeito cognoscente, fatores intrínsecos a este sujeito e processos (mentais lógicos e não lógicos). É um sistema que busca a entrada (dados) no ambiente, tendo como subproduto a informação, e no qual todos estes elementos influenciam-se, interagem e se interrelacionam (CHERUBINI NETO, 2002; MARODIN, 2004; MARODIN e VARGAS, 2004).

De acordo com Cherubini Neto (2002), não se pode "transmitir" ou "transferir" conhecimento, mas sim, informações que serão captadas ou não, interpretadas ou não, ou seja, processadas ou não pelo receptor. O receptor ao qual se tenta "passar algum conhecimento"

\footnotetext{
${ }^{1}$ Tradução livre: um conhecimento intrínseco de uma pessoa. É o que é conhecido por alguém. Sempre se refere a um indivíduo que possui a capacidade de implementar algo, o conhecimento se embasa nas competências básicas do indivíduo.
}

Rev. GUAL., Florianópolis, Edição especial 2011, p.51-69. 


\section{A GESTÃO DO CONHECIMENTO APLICADA EM INSTITUIÇÕES DE ENSINO SUPERIOR - O CASO DA ASSOCIAÇÃO CATARINENSE DE FUNDAÇÕES EDUCACIONAIS}

estará ouvindo ou lendo frases que são compostas de palavras, e só processará e armazenará aquilo que, por exemplo, ele julgar importante (ISAAC e JOSSERAND, 2006).

O conhecimento pode ser definido como sendo uma combinação de instintos, idéias, informações, regras e procedimentos que guiam decisões e ações. É resultado de um processo de aprendizado, o que significa que pode ser utilizado para resolver problemas ou criar novos paradigmas pessoais. Nas organizações, o conhecimento é instrumentado e constituído por rotinas, processos, práticas e normas, além de documentos e experiências pessoais (SANTOS, 2001; SILVA et al., 2003).

\subsubsection{Conhecimento explícito}

O conhecimento explícito é o conhecimento capturado por um código ou linguagem que facilitam a comunicação. O conhecimento explícito implica o "saber-fazer" transmissível em uma linguagem formal e sistemática, que exige experiência direta do conhecimento (HALL e ANDRIANI, 2003, apud BODER e BOUTELITANE, 2005).

O conhecimento pode ser formalmente articulado ou codificado, mais facilmente transferido ou dividido, objetivo e acessível. No entanto, de acordo com Scarbrough et al. (2000), a gestão do conhecimento que se concentra na criação de estruturas de redes para transferir o conhecimento será severamente limitada em termos de contribuição à inovação. Supondo-se que se uma organização queira melhorar sua performance em termos de inovação, esta precisa privilegiar o conhecimento tácito, que é dificilmente transferível através de redes. É por isso que os autores se interessam pelo conhecimento tácito, com objetivo de demonstrar em que modo o conhecimento tácito pode ser visto como uma fonte de inovação (BODER e BOUTELITANE, 2005).

\subsubsection{Conhecimento tácito}

Na definição de Polanyi (1962) o conhecimento tácito é um conhecimento nãoverbalizável, intuitivo e não-articulável. Conforme Nonaka e Takeuchi (1994) e Polanyi (1962, 1966), o conhecimento tácito é adquirido por experiência de colaboração e torna-se difícil de articular, de formalizar e comunicar. Não pode ser comunicado diretamente de maneira codificada. Esta última trata de uma experiência direta, que não é confiável por intermédio de objetos trabalhados (BODER e BOUTELITANE, 2005). 


\section{A GESTÃO DO CONHECIMENTO APLICADA EM INSTITUIÇÕES DE ENSINO SUPERIOR - O CASO DA ASSOCIAÇÃO CATARINENSE DE FUNDAÇÕES EDUCACIONAIS}

Assim, Leonard e Sensiper (1998) explicam que o conhecimento tácito está ocultando-se, tornando-se cada vez mais intangível, subjetivo e espontâneo. O conhecimento tácito se elevou muito, das próprias experiências e provém diretamente do inconsciente ou do subconsciente (BODER e BOUTELITANE, 2005).

\subsection{Dimensões da Criação do Conhecimento}

NONAKA e TAKEUCHI explicam que a inovação organizacional pode ser apresentada por um modelo, chamado de "nova teoria da criação do conhecimento organizacional" (1997). Essa abordagem tem a sua epistemologia (distinção entre conhecimento tácito e explícito) e a sua ontologia (níveis de entidades criadoras do conhecimento individual, grupal, organizacional, interorganizacional). Essas duas dimensões relacionando-se dinamicamente geram a espiral do conhecimento. (LIMA e GOSLING, 2005; BILICH et al., 2005; BALESTRIN, VARGAS e FAYARD, 2005; BALESTRIN e VARGAS, 2004).

Em termos da dimensão ontológica, sabe-se que o conhecimento só é criado por indivíduos. Portanto, o conhecimento organizacional é criado a partir de um processo que amplia organizacionalmente o conhecimento criado pelos indivíduos. Em relação à dimensão epistemológica, os autores recorrem à POLANYI (1966, apud LIMA e GOSLING, 2005) para distinguir conhecimento tácito (pessoal, específico ao contexto, difícil de ser formulado e codificado, ou seja, têm elementos cognitivos-modelos mentais; além de elementos técnicos know-how concreto, habilidades, técnicas) do conhecimento explícito (transmissível em linguagem formal e sistemática, é o conhecimento da racionalidade, que independe do contexto). POLANYI (1966, LIMA e GOSLING, 2005) interessado no processo de transferência de conhecimento entre as pessoas, identificou três mecanismos diretos, tácitos e psicossociais para esse processo: (i) imitação (imitiation); (ii) identificação (identification) e (iii) aprender fazendo (learning by doing).

Apesar de distintas, as duas dimensões do conhecimento não são mutuamente excludentes, outrossim, complementares. E então, tem-se que a criação do conhecimento organizacional depende da relação dinâmica entre conhecimento tácito e explícito. Takeuchi (1998, apud LIMA e GOSLING, 2005), ressalta que o conhecimento explícito pode ser processado por um computador, transmitido eletronicamente, ou armazenado em um banco de 


\section{A GESTÃO DO CONHECIMENTO APLICADA EM INSTITUIÇÕES DE ENSINO SUPERIOR - O CASO DA ASSOCIAÇÃO CATARINENSE DE FUNDAÇÕES EDUCACIONAIS}

dados. Para que o conhecimento tácito seja comunicado e compartilhado, ele tem que ser entendido pelas pessoas. É precisamente durante esse tempo de conversão, ou seja, do conhecimento tácito ao explícito, que o conhecimento organizacional é criado.

\subsection{Os quatro modos de conversão do conhecimento}

O modelo dos autores baseia-se no fato de que o conhecimento humano é criado e expandido através de interação social entre o conhecimento tácito e o explícito, o que se denomina conversão do conhecimento. Dessa forma, existem quatro formas de conversão de conhecimento, a saber: a socialização; a externalização; a combinação e a internalização (LIMA e GOSLING, 2005).

Para compreender a natureza do conhecimento e suas dimensões na organização é preciso destacar as formas de conversão do conhecimento, que segundo Nonaka e Takeuchi (1997), são os descritos a seguir.

A socialização liga-se às teorias dos processos de grupo e de cultura organizacional, e diz respeito à conversão conhecimento tácito em conhecimento tácito, ou seja, ao compartilhamento de experiências, de modelos mentais e de habilidades técnicas. No contexto de negócios, o treinamento prático gera esse compartilhamento de experiências. Para DAVENPORT e PRUSAK (1998), o único meio de se ensinar ou transferir (conhecimento tácito) é através da observação, por um longo prazo, da pessoas que o detém. Pode-se começar a compartilhar o conhecimento formalizando-se as redes informais já existentes. Outra forma é manter as comunidades de prática.

Para Stewart (1998, apud LIMA e GOSLING, 2005), as comunidades de prática são as oficinas, tendo como características o fato de serem grupos que têm histórias (aprendizado ao longo do tempo); têm um empreendimento, ou seja, formam-se para tentar agregar valor a algo de que todos participam; e , finalmente, esse empreendimento envolve aprendizado. Justamente por isso que as comunidades de prática, ao longo do tempo, desenvolvem costumes, cultura.

Socialização (conversão do Conhecimento Tácito em Conhecimento Tácito) - é um processo de compartilhamento de experiências e, a partir daí, da criação do conhecimento tácito, como modelos mentais ou habilidades técnicas compartilhadas. A forma mais 


\section{A GESTÃO DO CONHECIMENTO APLICADA EM INSTITUIÇÕES DE ENSINO SUPERIOR - O CASO DA ASSOCIAÇÃO CATARINENSE DE FUNDAÇÕES EDUCACIONAIS}

freqüente é aprender através da observação, da imitação e da prática, onde a base é a experiência (MACKE, 2005).

A externalização tem sido um pouco negligenciada pelas empresas, sendo um processo de articulação de conhecimentos tácitos em explícitos, expressos na forma de metáforas, analogias, conceitos, hipóteses e modelos. Isso pode ser conseguido combinandose dedução e indução. Quando isso não é possível, recorre-se à metáfora e/ou analogia, para se elaborar um conceito. Nota-se, assim, que a externalização é a chave para a criação de conhecimento, pois cria conceitos novos e explícitos a partir do conhecimento tácito (NONAKA e TAKEUCHI, 1997, apud LIMA e GOSLING, 2005). Para tal, faz-se o uso seqüencial da metáfora, analogia e modelo. A metáfora é uma forma de perceber intuitivamente uma coisa através de outra sendo, então, importante para a criação de uma "rede" novos conceitos. Já a analogia, harmoniza possíveis contradições das metáforas, ajudando a entender o desconhecido através do conhecido, eliminando a lacuna entre imagem e modelo lógico.

Externalização (conversão do Conhecimento Tácito em Conhecimento Explícito) - é um processo de articulação do conhecimento tácito em conceitos explícitos (expressos em forma de metáforas, analogias ou modelos). Quando se tenta conceituar uma imagem, ela é expressa basicamente através de uma linguagem (MACKE, 2005).

A combinação é a conversão de conhecimento explícito em conhecimento explícito, baseando-se no processamento de informações. Isso é conseguido através de documentos, reuniões, conversas ao telefone, redes de comunicação computadorizada, bancos de dados (LIMA e GOSLING, 2005).

Combinação (conversão do Conhecimento Explícito em Conhecimento Explícito) - é um processo de sistematização de conceitos de um sistema de conhecimentos. Envolve a combinação de conjuntos diferentes de conhecimentos explícitos, através de documentos, conversas, reuniões ou redes de comunicação. Esta combinação pode gerar novos conhecimentos explícitos (MACKE, 2005).

A internalização, ou seja, a conversão de conhecimento explícito em tácito, estando diretamente relacionada com o aprendizado organizacional, ocorre através da prática (aprender fazendo). Para a viabilização dessa conversão de conhecimento que ocorre na internalização, é necessário que o conhecimento seja verbalizado ou registrado, seja através

Rev. GUAL., Florianópolis, Edição especial 2011, p.51-69. 


\section{A GESTÃO DO CONHECIMENTO APLICADA EM INSTITUIÇÕES DE ENSINO SUPERIOR - O CASO DA ASSOCIAÇÃO CATARINENSE DE FUNDAÇÕES EDUCACIONAIS}

de documentos, banco de dados, manuais ou mesmo histórias orais. É importante ressaltar que o conhecimento tácito passa a fazer parte da cultura organizacional a partir do momento em que a maioria dos membros da organização passa a compartilhar de determinado modelo mental (LIMA e GOSLING, 2005).

Internalização (conversão do Conhecimento Explícito em Conhecimento Tácito) - é um processo de incorporação do conhecimento explícito no conhecimento tácito - está intimamente relacionada ao aprender fazendo. As experiências através da socialização, externalização e combinação, quando são internalizadas nas bases do conhecimento tácito dos indivíduos sob forma de modelos mentais ou know-how técnico compartilhado, tornam-se ativos valiosos (MACKE, 2005).

\section{METODOLOGIA}

O presente estudo se caracteriza pela produção de conhecimento do geral para o particular e do particular para o geral, tratando-se do emprego do método dedutivo e indutivo.

A pesquisa pretendida caracteriza-se como um estudo quantitativista de uso de dados qualitativos utilizando-se de estudo de caso transversal com nível de análise do tipo descritivo, apoiadas por investigação de dados secundários (análise documental) e primárias (formulários preenchido por informantes chave).

O caso deve ser uma referência significativa para merecer a investigação e apto para fazer generalizações similares, ou autorizar inferências em relação ao contexto da situação analisada (CHIZZOTTI, 1998).

$\mathrm{Na}$ primeira fase, pesquisou-se a literatura pertinente para fundamentação teórica (GODOY, 1995[a], GODOY, 1995[b], GODOY, 1995[c]). O estudo de caso (YIN, 2001) engloba a ACAFE, que congrega as Instituições de Ensino Superior Comunitárias localizadas no Estado de Santa Catarina. São elas: Unifebe, Unibave, FEHH, Unidavi, Unerj, Furb, Uniplac, Unesc, Univille, Univali, Unisul, Udesc, UnC, Unoesc, Unochapecó e USJ.

$\mathrm{Na}$ impossibilidade de se viabilizar um estudo qualitativo em todas as instituições da ACAFE, optou-se pela amostra intencional. A delimitação do estudo leva em conta a Associação que congrega todas as IESs catarinenses, sendo suficiente para delimitar o processo de conversão do conhecimento existente entre tais instituições. 


\section{A GESTÃO DO CONHECIMENTO APLICADA EM INSTITUIÇÕES DE ENSINO SUPERIOR - O CASO DA ASSOCIAÇÃO CATARINENSE DE FUNDAÇÕES EDUCACIONAIS}

Conforme Richardson (1989), a amostra intencional é formada por elementos relacionados intencionalmente de acordo com certas características estabelecidas nas hipóteses definidas pelo pesquisador.

As entrevistas semi-estruturadas foram dirigidas ao nível estratégico da ACAFE, escolhido pela qualidade de informações das quais dispõe. A técnica para coleta de dados deuse pela entrevista semi-estruturada e também pela análise documental (TRIVIÑOS, 1987).

Os dados foram analisados pela técnica de análise de conteúdo (MINAYO et al., 1994; BARDIN, 1977). Os dados, depois de reduzidos, foram categorizados e avaliados de acordo com os postulados de Collis e Hussey (2005).

Como limitações, o estudo possui aplicações ao modelo de IESs catarinenses, investigadas em maio de 2006, onde os resultados identificados não necessariamente se aplicam a outros casos, em outros momentos.

\section{APRESENTAÇÃO E DISCUSSÃO DOS RESULTADOS}

\subsection{Caracterização da ACAFE}

A ACAFE foi criada no dia 2 de maio de 1974 com o nome de Associação Catarinense das Fundações Educacionais, na forma de instituição civil sem fins lucrativos. A sua finalidade é a de congregar as Fundações Educacionais criadas pelo Governo do Estado e pelas Prefeituras de cidades do interior de Santa Catarina. Seus objetivos são o de promover o desenvolvimento das instituições mantidas por essas Fundações e de implementar atividades de interesse comum que assegurem a melhoria da qualidade do ensino superior no Estado (ACAFE, 2006; ACAFE, 2004).

Desde a sua criação a ACAFE vem implementando esforços visando ao alcance dos seus objetivos, defendendo os interesses do Sistema Catarinense de Ensino Superior. Ao longo dessas três décadas o Sistema passou por notáveis avanços: as faculdades isoladas originais foram consolidadas, expandiram sua capacidade de atendimento, diversificaram a oferta de cursos, formaram milhares de jovens profissionais, qualificaram seus professores, implantaram uma rede de laboratórios e bibliotecas e incorporaram atividades de pesquisa e de extensão (ACAFE, 2006).

Nos últimos 20 anos a grande maioria dessas instituições transformou-se em universidades e centros universitários, com campi espalhados por todo o território catarinense. 


\section{A GESTÃO DO CONHECIMENTO APLICADA EM INSTITUIÇÕES DE ENSINO SUPERIOR - O CASO DA ASSOCIAÇÃO CATARINENSE DE FUNDAÇÕES EDUCACIONAIS}

As Fundações Educacionais criadas por leis estadual e municipais constituem uma experiência nova no cenário do ensino superior brasileiro. Públicas na sua origem e no modo de organização, elas nasceram sob a inspiração do Poder Público e a participação de lideranças políticas e empresariais locais. O Governo do Estado criou a Fundação que deu origem à Universidade para o Desenvolvimento do Estado de Santa Catarina, exemplo adotado pelas Prefeituras Municipais de cidades do interior, pólos de desenvolvimento então emergentes nas diversas regiões econômicas do Estado (ACAFE, 2006; ACAFE, 2004).

A figura a seguir ilustra a abrangência das IESs componentes do Sistema ACAFE.

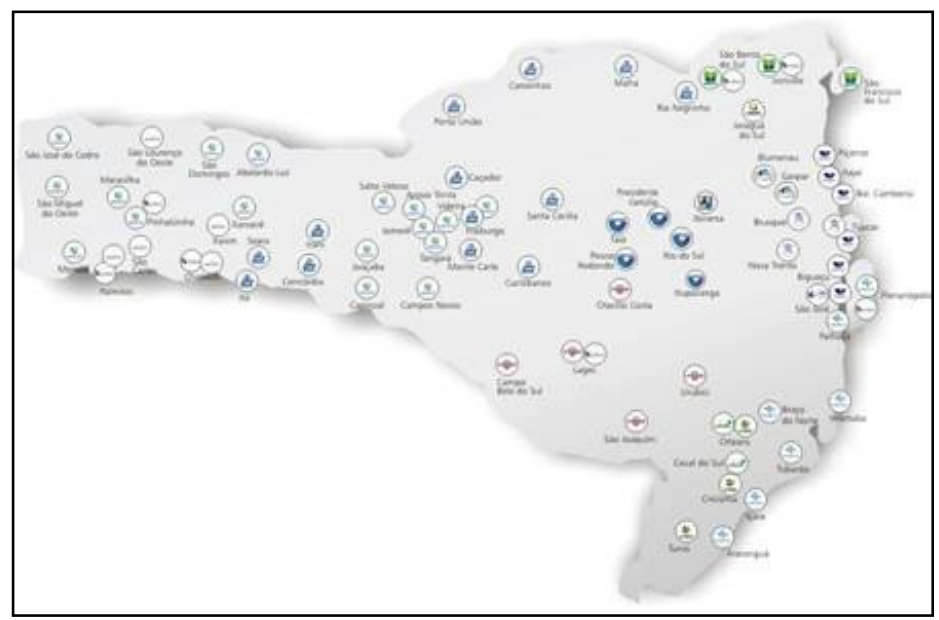

Figura 1 Mapa do Sistema Acafe.

Fonte: ACAFE, 2006.

As Fundações Educacionais criadas pelos Municípios implantaram Escolas Superiores orientadas para as suas próprias necessidades de desenvolvimento, com prioridade para a formação de quadros para o magistério, para a administração pública municipal e para a formação profissional de interesse do empresariado local. A consolidação desses empreendimentos educacionais, a expansão da oferta de vagas, a melhoria das condições de funcionamento e a qualificação do pessoal docente de cada uma delas foram determinantes para a transformação de grande parte daquelas primeiras instituições isoladas em universidades e centros universitários, a maioria com estrutura multi-campi. Hoje, o Sistema Fundacional está presente em 64 cidades do Estado de Santa Catarina, assegurando cobertura próxima para toda a sua população (ACAFE, 2006).

O Sistema Catarinense de Ensino Superior, enquanto estrutura de ensino superior integrada através de políticas estabelecidas de forma colegiada e articulada, é exemplo único 
no País. As 20 Fundações Educacionais filiadas à ACAFE e as 11 universidades, 2 centros universitários e 3 faculdades por elas mantidas, abrigam 140 mil alunos e respondem por cerca de $69 \%$ da matrícula em cursos superiores no Estado (percentual calculado com base em dados de 2003). Para atender a essa população estudantil as Fundações mantêm mais de 6 mil funcionários e mais de 9 mil professores; suas bibliotecas contam com acervo superior a 1 milhão de livros e centenas de laboratórios, através dos quais estão institucionalizados mais de 400 núcleos de pesquisa científica e tecnológica (ACAFE, 2006).

Além das atividades de ensino e pesquisa, as instituições de ensino mantêm inúmeros programas de assistência comunitária e de integração com as empresas. No ano de 2003, mais de 2,2 milhões de pessoas foram beneficiadas por algum tipo de ação comunitária (atendimento médico-hospitar, odontológico, psicológico, fisioterapêutico, jurídico e educacional) e de promoção cultural ou sócio-econômica. A integração entre as instituições de ensino, o governo e as empresas foram implementadas através de 1.600 acordos de cooperação e assistência técnica e científica (ACAFE, 2006).

\subsection{Apresentação dos dados da pesquisa}

Buscando conhecer o processo de conversão do conhecimento em uma associação de instituições de ensino superior, apresentam-se os resultados após efetuada a análise de conteúdo das informações levantadas durante a aplicação da entrevista semi-guiada.

Foram identificados vinte e quatro fatores relacionados com a conversão do conhecimento em IESs, os quais foram relacionados com as demais formas de conversão, através de uma escala "grande", "médio" e "baixo" grau de conversão de acordo com o fator identificado.

O quadro a seguir sintetiza e relaciona os fatores e a forma de conversão identificada. 


\section{A GESTÃO DO CONHECIMENTO APLICADA EM INSTITUIÇÕES DE ENSINO SUPERIOR - O CASO DA ASSOCIAÇÃO CATARINENSE DE FUNDAÇÕES EDUCACIONAIS}

\begin{tabular}{|c|c|c|c|c|}
\hline Itens & Socialização & Externalização & Combinação & Internalização \\
\hline $\begin{array}{l}\text { 1. Reuniões mensais de câmaras setoriais* para contribuir com idéias } \\
\text { e sugestões para melhoria de processos ou produtos. }\end{array}$ & Grande & Grande & Grande & Médio \\
\hline $\begin{array}{l}\text { 3. Análises e avaliações de processos foram constituídos e está em } \\
\text { fase de implantação. }\end{array}$ & Baixo & Médio & Médio & Baixo \\
\hline $\begin{array}{l}\text { 4. Grupos ad hoc são formados para unificar procedimentos e } \\
\text { deflagrar ações conjuntas. }\end{array}$ & Grande & Grande & Grande & Grande \\
\hline \begin{tabular}{|l} 
5. Palestras direcionadas às câmaras setoriais incentivam o \\
compartilhamento e difusão de conhecimentos.
\end{tabular} & Grande & Médio & Médio & Baixo \\
\hline $\begin{array}{l}\text { 6. Folders traduzidos para outros idiomas e site na internet são } \\
\text { mecanismos de referência sobre as IESs na busca de informações. }\end{array}$ & Médio & Baixo & Baixo & Baixo \\
\hline $\begin{array}{l}\text { 9. Cada IES tem um plano de cargos e salários específico. Não há } \\
\text { informações sobre premiação salarial pela participação no processo } \\
\text { de geração de novos conhecimentos. }\end{array}$ & Baixo & Baixo & Baixo & Baixo \\
\hline $\begin{array}{l}\text { 10. Não há mecanismos de interação com o ambiente externo } \\
\text { (mercados, concorrentes, novos insumos, etc). }\end{array}$ & Médio & Médio & Médio & Médio \\
\hline $\begin{array}{l}\text { 11. Não há mecanismos formais de acompanhamento do ambiente } \\
\text { externo. }\end{array}$ & Médio & Médio & Médio & Baixo \\
\hline $\begin{array}{l}\begin{array}{l}\text { 12. Decisões consensuadas entre as IESs são documentadas e } \\
\text { arquivadas. }\end{array} \\
\end{array}$ & Grande & Grande & Grande & Médio \\
\hline $\begin{array}{l}\text { 16. A interação e comunicação entre os membros de câmaras setoriais } \\
\text { se dá pela forma de listas eletrônicas, para troca de informações e } \\
\text { experiências. }\end{array}$ & Grande & Grande & Grande & Grande \\
\hline $\begin{array}{l}\text { 17. Informações captadas fora da ACAFE são compartilhadas em } \\
\text { reuniões, como troca de informações e experiências e como forma de } \\
\text { aperfeiçoamento de processos. }\end{array}$ & Grande & Médio & Grande & Médio \\
\hline $\begin{array}{l}\text { 18. Mudanças organizacionais e novas práticas gerenciais são fatores } \\
\text { que afetam estratégias de desenvolvimento tecnológico. }\end{array}$ & Baixo & Baixo & Baixo & Baixo \\
\hline $\begin{array}{l}\text { 19. Inovação de processos é a ação que visa o desenvolvimento } \\
\text { tecnológico. }\end{array}$ & Médio & Médio & Baixo & Baixo \\
\hline $\begin{array}{l}\text { Es. Escassez de recursos financeiros próprios é a dificuldade } \\
\text { principal para o planejamento e desenvolvimento. }\end{array}$ & Baixo & Baixo & Baixo & Baixo \\
\hline $\begin{array}{l}\text { 21. Serviços de assistência técnica e científica são os canais de } \\
\text { transferência de tecnologia utilizados. }\end{array}$ & Médio & Baixo & Baixo & Baixo \\
\hline $\begin{array}{l}\text { 22. Fontes internas próprias são as principais fontes de informação e } \\
\text { conhecimento para o desenvolvimento tecnológico. }\end{array}$ & Grande & Grande & Grande & Grande \\
\hline $\begin{array}{l}\text { 23. Há preocupação em todos os momentos com a segurança do } \\
\text { conhecimento desenvolvido e/ou adquirido. }\end{array}$ & Grande & Grande & Baixo & Médio \\
\hline $\begin{array}{l}\text { 24. Não há mecanismos de proteção do conhecimento desenvolvido } \\
\text { e/ou adquirido. }\end{array}$ & Baixo & Baixo & Baixo & Baixo \\
\hline
\end{tabular}

QUADRO 01 Fatores e a formas de conversão do conhecimento identificados na ACAFE Fonte: Dados primários.

* Câmaras setoriais: são sete câmaras nas áreas de graduação; pós-graduação, pesquisa e inovação tecnológica; extensão, cultura e comunidades; tecnologias de informação e comunicação; bibliotecas; assuntos jurídicos, administração e desenvolvimento institucional; e educação à distância. 


\section{A GESTÃO DO CONHECIMENTO APLICADA EM INSTITUIÇÕES DE ENSINO SUPERIOR - O CASO DA ASSOCIAÇÃO CATARINENSE DE FUNDAÇÕES EDUCACIONAIS}

\subsection{Discussão dos resultados}

A pesquisa evidencia que existem fatores determinantes para a geração e difusão do conhecimento entre as IES's, conforme as afirmações: criação de grupos ad hoc formados para unificar procedimentos e deflagrar ações conjuntas; decisões são tomadas em colegiado, registrando atribuições e encaminhamentos para cada IES's; a interação e comunicação entre os membros de câmaras setoriais se dá pela forma de listas eletrônicas, para troca de informações e experiências; e as fontes internas próprias são as principais fontes de informação e conhecimento para o desenvolvimento tecnológico.

Também merece destaque pontos positivos que garantem um processo de conversão do conhecimento mais completo entre as IES's pesquisadas, são: reuniões mensais de câmaras setoriais para contribuir com idéias e sugestões para melhoria de processos ou produtos; decisões consensuadas entre as IES's são documentadas e arquivadas; relatórios demonstram resultados comprovando a decisão pela continuidade ou não de experimentos; e o site da ACAFE na internet permite acesso a documentos apenas por pessoas cadastradas.

Maior atenção deve ser dada aos quesitos: palestras direcionadas às câmaras setoriais incentivam o compartilhamento e difusão de conhecimentos; contatos cadastrados por câmara setorial recebem por e-mail documentos e informações obtidos fora da ACAFE; informações captadas fora da ACAFE são compartilhadas em reuniões, como troca de informações e experiências e como forma de aperfeiçoamento de processos; e a preocupação em todos os momentos com a segurança do conhecimento desenvolvido e/ou adquirido.

É preciso rever os mecanismos de interação com o ambiente externo (mercados, concorrentes, novos insumos, etc), pois constatou-se a inexistência desta relação entre IES's e ambiente externo, o que é fundamental à elaboração de estratégias, por exemplo, o que afeta a constituição de conhecimentos internos. Além deste, recomenda-se uma especial atenção aos treinamentos em todos os níveis hierárquicos em cada IES e um maior envolvimento da ACAFE neste processo; e pela inexistência de mecanismos formais de acompanhamento do ambiente externo.

\section{CONCLUSÃO}

Percebe-se que, muito embora existam necessidades de reforço no que tange a interação com o ambiente externo, treinamentos em diversos níveis hierárquicos 


\section{A GESTÃO DO CONHECIMENTO APLICADA EM INSTITUIÇÕES DE ENSINO SUPERIOR - O CASO DA ASSOCIAÇÃO CATARINENSE DE FUNDAÇÕES EDUCACIONAIS}

acompanhados pela ACAFE e criação de mecanismos formais de acompanhamento ambientais, existem quatro fatores de grande importância e que garantem a geração e difusão do conhecimento na ACAFE, são eles: criação de grupos ad hoc formados para unificar procedimentos e deflagrar ações conjuntas; decisões são tomadas em colegiado, registrando atribuições e encaminhamentos para cada IESs; a interação e comunicação entre os membros de câmaras setoriais se dá pela forma de listas eletrônicas, para troca de informações e experiências; e as fontes internas próprias são as principais fontes de informação e conhecimento para o desenvolvimento tecnológico.

Tendo em vista que o gerenciamento do conhecimento é a base da empresa inovadora, percebe-se que a ACAFE encontra-se em estágio avançado na gestão deste conhecimento, necessitando fortalecer os conhecimentos captados fora da ACAFE e considerados na elaboração de estratégias, além da segurança e proteção do conhecimento desenvolvido e/ou adquirido.

\section{REFERÊNCIAS}

ACAFE, Associação Catarinense de Fundações Educacionais. Histórico. Disponível em: $<$ http://www.acafe.org.br>. Acesso em 16 mai. 2006.

ACAFE, Associação Catarinense de Fundações Educacionais. Perfil ACAFE 30 anos. ACAFE: Florianópolis, 2004.

ALMANSA, Alberto, et al. "La gestión del conocimiento en España - 2001.” IESE Business School. Universidad de Navarra: Navarra, 2002. Disponível em: $<$ http://www.capgemini.es/docs /Documento7_001.pdf>. Acesso em: 29 abr. 2006.

BALESTRIN, Alsones, VARGAS, Lilia Maria. A complementaridade de conhecimentos nos processos de inovação. In: XXVIII ENANPAD, Anais, 2004.

BALESTRIN, Alsones, VARGAS, Lilia, FAYARD, Pierre. "Ampliação interorganizacional do conhecimento: o caso das redes de cooperação." Revista eletrônica de administração. 43 ed. Disponível em: < http://read.ea.ufrgs.br/edicoes/pdf/artigo_316.zip>. vol. 11, n. 1, jan.fev./05. 2005. Acesso em 29 abr. 2006.

BARDIN, L. Análise de conteúdo. Lisboa, Edições 70, 1977.

BILICH, Feruccio, et al. "Innovation management of intellectual capital in research and development." Revista eletrônica de administração. 44 ed. Disponível em: $<$ http://read. ea.ufrgs.br/edicoes/pdf/artigo_324.zip >. vol. 11, n. 2, mar.-abr./05. 2005. Acesso em: 29 abr. 2006.

Rev. GUAL., Florianópolis, Edição especial 2011, p.51-69. 
BODER, André, BOUTELITANE, Salima. "Management des connaissances et processus d'innovation." Faculte des Sciences Economiques et Sociales - Hautes Etudes Commerciales/HEC-Genève. Disponível em: <http://www.hec.unige.ch/recherches publications/cahiers/2005/2005.02.pdf>. 2005. Acesso em: 29 abr. 2006.

CHERUBINI NETO, Reinaldo. "O que é conhecimento? Sintetizando epistemologia, metodologia e teoria de sistemas em uma nova proposição." Revista eletrônica de administração. $25 \mathrm{ed}$. Available at: <http://www.read.ea.ufrgs.br/edicoes/ pdf/artigo_113.zip>. vol. 8, n. 1, jan.-fev./02. 2002. Acesso em: 29 abr. 2006.

CHIZZOTTI, Antônio. Pesquisa em ciências humanas e sociais. 3. ed., São Paulo: Cortez, 1998.

COLLIS, Jill, HUSSEY, Roger. Pesquisa em administração: um guia prático para alunos de graduação e pós-graduação. 2. ed., Porto Alegre: Bookman, 2005.

DAVENPORT, T. H.; PRUSAK, L. Conhecimento empresarial: como as organizações gerenciam o seu capital intelectual. Rio de Janeiro: Campus, 1998.

GODOY, Arilda Schmidt. A pesquisa qualitativa e sua utilização em administração de empresas. Revista de administração de empresas. São Paulo, v. 35, n. 4, mar./abr. 1995[c].

GODOY, Arilda Schmidt. Introdução à pesquisa qualitativa e suas possibilidades. Revista de administração de empresas. São Paulo, v. 35, n. 2, mar./abr. 1995[a].

GODOY, Arilda Schmidt. Pesquisa qualitativa: tipos fundamentais. Revista de administração de empresas. São Paulo, v. 35, n. 3, mar./abr. 1995[b].

ISAAC, Henri, JOSSERAND, Emmanuel. "Structure et systeme d'information: quels roles dans les pratiques de gestion de la connaissance?" Centre de Recherche en Management \& Organisation - Universitè de Paris - Dauphine. Disponível em: $<\mathrm{http}: / / \mathrm{www} . c r e p a$. dauphine.fr/ArticleCahierRecherche/Conferences/agrh14mai2002/11\%20JosserandIsaac.pdf> . Acesso em: 29 abr. 2006.

LIMA, Ana Catarina Silva, GOSLING, Marlusa. "A espiral do conhecimento: uma experiência em processo de desenvolvimento de software dentro da universidade." Revista eletrônica de administração. 45 ed. Disponível em: $<$ http://www.read.ea.ufrgs.br /edicoes/pdf/artigo_333.zip>. vol. 11, n. 3, mai.-jun./05. 2005. Acesso em: 29 abr. 2006.

MACKE, Janaina. "Organização do trabalho e inovações sistêmicas: um panorama histórico das mudanças na natureza do conhecimento." Revista eletrônica de administração. 46 ed. Disponível em: <http://www.read.ea.ufrgs.br/edicoes/pdf/artigo_367.zip>. vol. 11, n. 4, jul.ago./05. 2005. Acesso em: 29 abr. 2006.

MARODIN, Fabrizio Almeida, VARGAS, Lilia Maria. Estratégias de gestão de conhecimento e uso de tecnologia de informação: um estudo de caso em uma empresa de 
software. In: XXVIII ENANPAD, Anais, 2004.

MARODIN, Fabrizio Almeida. Estratégias de gestão de conhecimento e o uso de tecnologia de informação: um estudo de caso. 2004. 133 f. Dissertação (Mestrado)-Escola de Administração, Universidade Federal do Rio Grande do Sul, Porto Alegre, 2004. Disponível em: < http://www.ea.ufrgs.br/teses_e_dissertacoes/td/002940.pdf > . Acesso em 26 jul. 2005.

MINAYO, Maria C. S. et al. Pesquisa social. Petrópolis: Vozes, 1994.

NICOLAU, Isabel. "Gestão do conhecimento nas organizações e mercados de serviços." Instituto para o desenvolvimento da gestão empresarial - INDEG. Disponível em: $<$ http://213.13.125.90/portallizer/upload_ficheiros/02-02_Isabel_Nicolau.pdf $>$. 2002. Acesso em: 29 abr. 2006.

NONAKA, I. e TAKEUCHI, H. Criação de conhecimento na empresa. Rio de Janeiro: Campus, 1997.

RICHARDSON, Roberto Jarry, et al. Pesquisa social: métodos e técnicas. 2. ed., São Paulo: Atlas, 1989.

SANTOS, Zosymo Canto dos. A contribuição da gestão do conhecimento e da inteligência competitiva na estratégia de produção em curtumes. 2001. 113 f. Dissertação (Mestrado)Escola de Administração, Universidade Federal do Rio Grande do Sul, Porto Alegre, 2001. Disponível em: $<$ http://www.ea.ufrgs.br/teses_e_dissertacoes/td/0 00493.pdf $>$. Acesso em 26 jul. 2005.

SCHMUKLER, Adolfo, ALBINO, João Pedro. Tecnologia como fator crítico na gestão do conhecimento organizacional. In: EBOLI, Marisa (org.). Coletânea universidades corporativas: educação para as empresas do século XXI. Desenvolvimento e alinhamento de talentos humanos às estratégias empresariais: o surgimento das universidades corporativas. São Paulo: Schmukler editores, 1999. p. 168-183.

SILVA, Antonio Braz de O., et al. Gestão do conhecimento - um estudo sobre empresas do setor de informática em Minas Gerais. In: KM BRASIL, 2003, São Paulo, Anais. Disponível em $<$ http://www.netic.com.br/docs/publicacoes/pub0002.pdf > . Acesso em: 29 abr. 2006.

TRIVIÑOS, A. N. S. Introdução à pesquisa em ciências sociais: a pesquisa qualitativa em educação. São Paulo: Atlas, 1987.

YIN, Robert. Estudo de caso: planejamento e métodos. 2. ed., Porto Alegre: Bookman, 2001. 


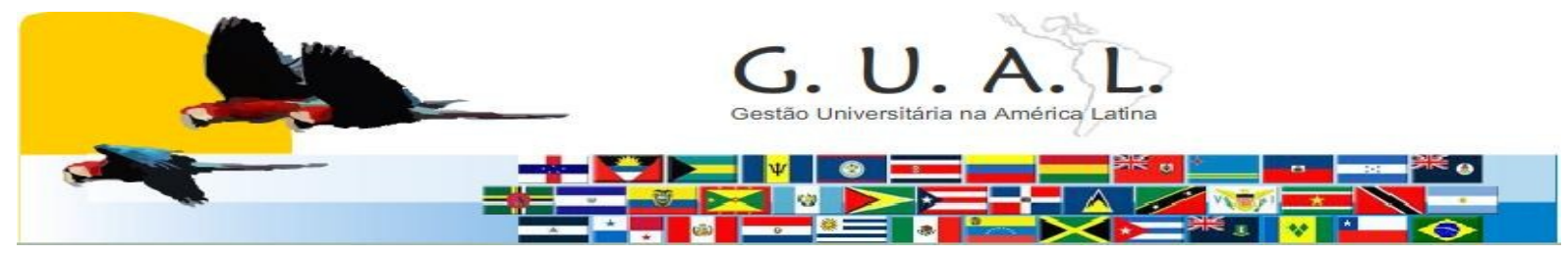

ISSN 1983-4535

\title{
KNOWLEDGE MANAGEMENT APPLIED ON INSTITUTIONS OF HIGHER EDUCATION: THE CASE OF CATARINIAN ASSOCIATION OF EDUCATIONAL FOUNDATIONS
}

\author{
Marcos Ferasso, Doctor \\ Universidade Federal do Piauí \\ admmarcos@admmarcos.adm.br \\ Jorge Alberto Velloso Saldanha, Doctor \\ Universidade Federal do Piaui \\ javsa@terra.com.br
}

\begin{abstract}
Human knowledge is created and expanded through social interaction between tacit and explicit knowledge, which is called knowledge conversion. Thus, there are four forms of knowledge conversion: socialization, externalization, combination and internalization. This case study seeks to investigate the configuration of the knowledge conversion process on Catarinian higher education institutions. Through this research, it was discovered that there are four major factors and which ensure the generation and dissemination of knowledge in ACAFE, they are: creation of $a d$ hoc groups formed to standardize procedures and to obtain joint actions, decisions are taken collegially recording assignments and responsibilities for each institution, the interaction and communication among members of sectoral chambers is by way of electronic lists to exchange information and experiences, and their own internal sources are the main sources of information and knowledge for technological development. It was perceived that ACAFE is at an advanced stage in the management of this knowledge, it is needed to strengthen the knowledge obtained outside the ACAFE considered in developing strategies, as well as safety and security of the knowledge developed and/or acquired.
\end{abstract}

Keywords: Knowledge management. Universitary management. ACAFE. 